\title{
A Study of 34 Cases of Paranasal Sinus Cysts with Orbital Symptoms
}

\author{
Takashi Taniyama ${ }^{1)}$, Tomonori Sugiyama ${ }^{2)}$, Mamika Araki ${ }^{2}$, Kouhei Fukukita $^{2)}$, \\ Hiroyuki Yamada ${ }^{2)}$, Yoshio Hatakeyama ${ }^{1)}$, Shinji Koyama ${ }^{1)}$ and Hiroshi Hosoi ${ }^{3)}$
}

Between 2001 and 2010, we treated 34 cases of paranasal sinus cysts with orbital symptoms. The subjects were 20 men and 14 women, aged 15 to 88 years (mean: 60.5 years). The paranasal sinus cysts were located in the frontal sinus in 15 cases, anterior ethmoid sinus in 12 cases, posterior ethmoid sinus in 8 cases, sphenoid sinus in 5 cases, and maxillary sinus in 2 cases. The symptoms included diplopia (9 cases), exophthalmos ( 8 cases), eyelid swelling ( 7 cases), visual disturbance ( 5 cases), orbital pain (4 cases), orbital discomfort ( 2 cases), and epiphora ( 2 cases). The cysts were postoperative in 24 cases and primary in 8 cases. Most patients tended to visit departments other than the department of otolaryngology, with only 5 patients initially visiting the department of otolaryngology. While the symptoms improved in 32 cases, little improvement was seen in 2 cases. Both of these latter symptoms 2 cases presented with visual disturbance. Therefore, early diagnosis and prompt treatment are essential for cases presenting with visual disturbance, as the symptoms may not respond satisfactorily to treatment if the treatment is delayed. Therefore, it is important for doctors in departments other than the department of otolaryngology also to be aware about this condition.

Keywords : paranasal sinus cyst, orbital symptom, visual disturbance

\section{References}

1）藤森正登, 中川雅文, 芳川 洋 : 当教室における副鼻腔囊 胞の検討. 耳鼻と臨 38: 247-251, 1992.

2）堀内博人，江崎史朗，内田 豊：いわゆる術後性篩骨洞囊 腫について. 耳鼻展望 25: 29-38, 1982.

3）武藤次郎，竹田英子，坊野馨二，他：術後性上顎囊胞の臨 床統計的観察. 聥信医 40:25-31, 1988.

4）福田宏治，金田裕治，佐藤宏昭，他：当科における過去 10 年間の副鼻腔囊胞の臨床的検討一術後性と原発性の比較 一。岩手医誌 55: 143-148, 2003.

5）市村恵一：副鼻腔囊胞性疾患. CLIENT21 12 巻 鼻（野 村恭也，小松崎篤，本庄 䕾編）。 321-331 頁，中山書店， 東京, 2000

6) Sakaida H, Kobayashi M, Yuta A, et al. : Clinical studies of idiopathic paranasal cysts. Pract Otol (Kyoto) 98: 377-380, 2005.

7）柳 清, 鴻 信義, 深見雅也, 他：術後性上顎囊胞に対
する内視鏡下鼻内手術．耳鼻展望 35：425-433, 1992.

8) Shimomura S, Nozawa I, Hisamatsu K, et al. : Cystic lesions of paranasal sinuses associated with orbital manifestations; a report of 60 patients. Pract Otol (Kyoto) Suppl 79: 110-117, 1995.

9) Ogawa Y, Sato H, Fujita H, et al. : Association of orbital symptoms with cystic lesion of the paranasal sinuses. Pract Otol (Kyoto) 91: 1127-1135, 1998.

10）成尾一彦, 中嶋真沙子, 西村忠己, 他 : 視器症状を呈した 副鼻腔囊胞の臨床的検討. 日鼻科会誌 49: 116-120, 2010.

11) Lawson $\mathrm{W}$ and Reino $\mathrm{AJ}$ : Isolated sphenoid sinus disease: an analysis of 132 cases. Laryngoscope 107: 1590-1595, 1997.

12）森山 寛, 島田和哉, 斎藤 建, 他 : 後部副鼻腔囊胞. 耳 鼻展望 24：465-480, 1981.

13）岡 正倫, 安松隆治, 吉川沙耶花, 他：当科における笠骨 洞・蝶形骨洞囊胞の臨床的検討. 耳鼻と臨 55: 142-146, 2009 .
1) Department of Otorhinolaryngology, Yamatotakada Municipal Hospital

2) Department of Head and Neck Otorhinolaryngology, Ise Red Cross Hospital

3) Department of Otorhinolaryngology Head and Neck Surgery, Nara Medical University
Corresponding Author Address : Takashi Taniyama

ta-taniyama@dolphin.ocn.ne.jp 
14）嶋根俊和，古矢彩子，森本雅太，他：眼症状を併発した副 鼻腔囊胞 5 例の臨床的検討. 耳鼻展望 49：124-130, 2006.

15）森山 寛，中島庸也，島田士郎，他：視力障害を伴う術後 性の後部副鼻腔囊胞例の検討. 耳鼻展望 31：803-811, 1988.

16）齊藤栄子, 藤本尚也, 安達恵美子, 他 : 視力零から回復し
た鼻性視神経症の 1例．臨眼 51：1905-1908, 1997.

17) Yumoto E, Hyodo M, Kawakita S, et al. : Mucoceles of the posterior paranasal sinuses and visual disturbance. Pract Otol (Kyoto) 89: 1105-1111, 1996.

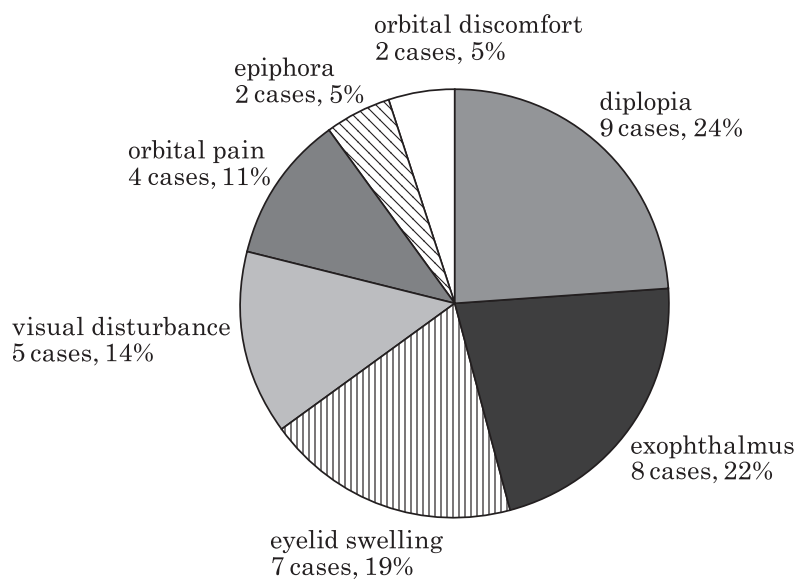

Chief complaint

Five cases showing visual disturbance

\begin{tabular}{c|c|l|l|c|c}
\hline \hline & Age, sex & Initial consult & \multicolumn{1}{|c|}{ Location of disease } & $\begin{array}{c}\text { Days before } \\
\text { the operation }\end{array}$ & $\begin{array}{c}\text { Visual acuity post-operation } \\
\text { (pre-operation) }\end{array}$ \\
\hline 1 & $54 \mathrm{M}$ & ophthalmology & Sphenoid sinus & 45 & 0.8 (finger movement) \\
\hline 2 & $57 \mathrm{~F}$ & ophthalmology & Sphenoid and posterior ethmoid sinus & 3 & $1.2(0.01)$ \\
\hline 3 & $65 \mathrm{~F}$ & ophthalmology & posterior ethmoid sinus & 4 & $0.9(0.01)$ \\
\hline 4 & $55 \mathrm{M}$ & ophthalmology & posterior ethmoid sinus & 1 & 0.04 (finger movement) \\
\hline 5 & $88 \mathrm{~F}$ & ophthalmology & posterior ethmoid sinus & 21 & 0.02 (light sense)
\end{tabular}

